\title{
Germline breast cancer susceptibility genes, tumor characteristics, and survival
}

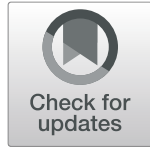

Peh Joo Ho ${ }^{1,2}$, Alexis J. Khng ${ }^{1}$, Hui Wen Loh', Weang-Kee Ho ${ }^{3,4}$, Cheng Har Yip ${ }^{5}$, Nur Aishah Mohd-Taib ${ }^{6,7}$, Veronique Kiak Mien Tan ${ }^{8,9}$, Benita Kiat-Tee Tan ${ }^{8,9,10}$, Su-Ming Tan ${ }^{11}$, Ern Yu Tan ${ }^{12,13,14}$, Swee Ho Lim ${ }^{15}$, Suniza Jamaris ${ }^{6,7}$, Yirong Sim ${ }^{8,9}$, Fuh Yong Wong ${ }^{16}$, Joanne Ngeow ${ }^{17,18,19}$, Elaine Hsuen Lim² ${ }^{20}$, Mei Chee Tai ${ }^{4}$, Eldarina Azfar Wijaya ${ }^{4}$, Soo Chin Lee ${ }^{21}$, Ching Wan Chan ${ }^{22}$, Shaik Ahmad Buharii ${ }^{22}$, Patrick M. Y. Chan ${ }^{12}$, Juliana J. C. Chen ${ }^{12}$, Jaime Chin Mui Seah ${ }^{11}$, Wai Peng Lee ${ }^{11}$, Chi Wei Mok ${ }^{11}$, Geok Hoon Lim ${ }^{15}$, Evan Woo ${ }^{15}$, Sung-Won Kim², Jong Won Lee ${ }^{24}$, Min Hyuk Lee ${ }^{25}$, Sue K. Park ${ }^{26,27,28}$, Alison M. Dunning ${ }^{29}$, Douglas F. Easton ${ }^{29,30}$, Marjanka K. Schmidt ${ }^{31}$, Soo-Hwang Teo ${ }^{4,32}$, Jingmei $\mathrm{Li}^{1,33^{*+}}$ (D) and Mikael Hartman 2,22,33†

\begin{abstract}
Background: Mutations in certain genes are known to increase breast cancer risk. We study the relevance of rare protein-truncating variants (PTVs) that may result in loss-of-function in breast cancer susceptibility genes on tumor characteristics and survival in 8852 breast cancer patients of Asian descent.

Methods: Gene panel sequencing was performed for 34 known or suspected breast cancer predisposition genes, of which nine genes (ATM, BRCA1, BRCA2, CHEK2, PALB2, BARD1, RAD51C, RAD51D, and TP53) were associated with breast cancer risk. Associations between PTV carriership in one or more genes and tumor characteristics were examined using multinomial logistic regression. Ten-year overall survival was estimated using Cox regression models in 6477 breast cancer patients after excluding older patients ( $\geq 75 y$ years) and stage 0 and IV disease.

Results: PTV 9 genes carriership $(n=690)$ was significantly associated $(p<0.001)$ with more aggressive tumor characteristics including high grade (poorly vs well-differentiated, odds ratio [95\% confidence interval] 3.48 [2.355.17], moderately vs well-differentiated 2.33 [1.56-3.49]), as well as luminal B [HER-] and triple-negative subtypes (vs luminal A 2.15 [1.58-2.92] and 2.85 [2.17-3.73], respectively), adjusted for age at diagnosis, study, and ethnicity. Associations with grade and luminal B [HER2-] subtype remained significant after excluding BRCA1/2 carriers. PTV 25 genes carriership ( $n=289$, excluding carriers of the nine genes associated with breast cancer) was not


to be associated with worse 10-year overall survival (hazard ratio [C] 1.63 [1.16-2.28]).
\end{abstract}

\footnotetext{
* Correspondence: lijm1@gis.a-star.edu.sg

${ }^{\dagger}$ Jingmei Li and Mikael Hartman contributed equally to this work.

${ }^{1}$ Genome Institute of Singapore, Human Genetics, Singapore, Singapore

${ }^{33}$ Department of Surgery, Yong Loo Lin School of Medicine, National

University of Singapore and National University Health System, Singapore,

Singapore

Full list of author information is available at the end of the article
}

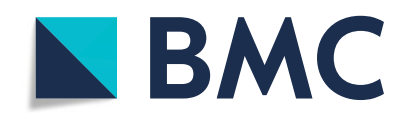

(c) The Author(s). 2021 Open Access This article is licensed under a Creative Commons Attribution 4.0 International License, which permits use, sharing, adaptation, distribution and reproduction in any medium or format, as long as you give appropriate credit to the original author(s) and the source, provide a link to the Creative Commons licence, and indicate if changes were made. The images or other third party material in this article are included in the article's Creative Commons licence, unless indicated otherwise in a credit line to the material. If material is not included in the article's Creative Commons licence and your intended use is not permitted by statutory regulation or exceeds the permitted use, you will need to obtain permission directly from the copyright holder. To view a copy of this licence, visit http://creativecommons.org/licenses/by/4.0/. The Creative Commons Public Domain Dedication waiver (http://creativecommons.org/publicdomain/zero/1.0/) applies to the data made available in this article, unless otherwise stated in a credit line to the data. 


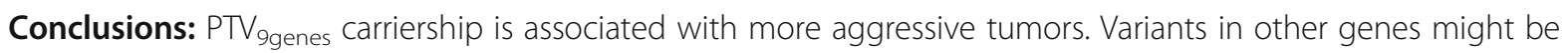
associated with the survival of breast cancer patients. The finding that PTV carriership is not just associated with higher breast cancer risk, but also more severe and fatal forms of the disease, suggests that genetic testing has the potential to provide additional health information and help healthy individuals make screening decisions.

Keywords: Breast cancer, Protein-truncating variants, Overall survival

\section{Background}

Breast cancer is the most common cancer among women worldwide. Breast cancer manifestations are biologically and molecularly heterogeneous with a high degree of diversity observed between and within tumors. Such phenotypic differences in tumor characteristics are clinically informative because they are prognostic and can improve therapy selection $[1,2]$. In particular, profiling of breast cancer can be based on the expressions of three immunohistochemical markers: estrogen receptor (ER), progesterone receptor (PR), and human epidermal growth factor receptor (HER2). Patients with ER- and PR-positive breast cancer respond well to endocrine therapy and have favorable outcomes [1]. In contrast, tumors which were ER/PR and HER2 negative are associated with worse survival and are typically treated with chemotherapy and radiotherapy [1].

There is a strong genetic component to the risk of breast cancer [3]. A large majority of disease-associated variants in susceptibility genes are protein-truncating variants (PTVs), a class of variants that usually results in an absence of functional protein [4]. Pathogenic PTVs are typically rare (allele frequency $<1 \%$ ) and are usually associated with a twofold or higher risk of breast cancer [5].

Previously, Li et al. [6] observed, in a study of 5099 Swedish breast cancer patients, that tumors arising in PTV carriers with known or suspected predisposition genes were phenotypically more aggressive and had worse survival as compared to tumors in non-carriers. However, there is growing concern that genetic markers identified in populations of predominantly European ancestry may not be equally informative in non-European populations, due to the modifier effect of lifestyle and genetic factors which may be distributed differently in diverse populations [7]. Here, we attempt to study how rare variants in breast cancer predisposition genes are associated with tumor characteristics and survival in 8852 breast cancer patients of Asian descent.

\section{Methods}

\section{Study populations}

The study population was derived from the patients enrolled in the Singapore Breast Cancer Cohort (SGBCC), the Malaysian Breast Cancer Genetic Study (MyBrCa), and the Korean Hereditary Breast Cancer Study (KOHBRA).

\section{Singapore Breast Cancer Cohort (SGBCC)}

The Singapore Breast Cancer Cohort (SGBCC) study includes women aged 21 years and above diagnosed with either breast carcinoma in situ or invasive breast cancer at one of the six participating restructured hospitals in Singapore (National University Hospital, KK Women's and Children's Hospital, Tan Tock Seng Hospital, Singapore General Hospital, National Cancer Centre Singapore, Changi General Hospital). These six hospitals collectively diagnose and treat $\sim 76 \%$ of all breast cancer cases in Singapore [8]. Patients were a mixture of prevalent and incident cases from the three main ethnic groups, Chinese (81\%), Malay (13\%), and Indian (6\%). Ethnicity was self-reported. According to the 2010 census of Singapore, Indian ethnicity refers "to persons of Indian, Pakistani, Bangladeshi or Sri Lankan origin such as Tamils, Malayalis, Punjabis, Bengalis, Singhalese, etc." The ethnic distribution of SGBCC is similar to that of the general population of Singapore (Chinese 75.9\%, Malay 15\%, Indian 7.5\%, Department of Statistics Singapore). Between April 2010 and December 2016, 7768 breast cancer patients were recruited into SGBCC. Of which 4538 patients had genetic information from blood or saliva samples collected at recruitment. After excluding duplicated individuals $(n=9), 4529$ patients were included to test for associations between PTV carriership and tumor characteristics. A subset of 3213 patients were eligible for survival analysis.

\section{The Malaysian Breast Cancer Genetic Study (MyBrCa)}

The Malaysian Breast Cancer Genetic Study (MyBrCa), a hospital-based case-control study, was initiated in 2002 (described by Tan et al. [9]). Briefly, all patients diagnosed with breast cancer from two participating hospitals in Selangor, Malaysia (University Malaya Medical Centre, a public hospital, and Subang Jaya Medical Centre, a private hospital), were invited to participate. Participants were mainly from urban areas. These two hospitals treat more than $10 \%$ of the breast cancer cases in Malaysia [9]. The core ethnic groups of $\mathrm{MyBrCa}$ are Chinese (69\%), Malay (16\%), and Indian (12\%). In Malaysia, the predominant ethnic group is Malay 
(67.4\%), followed by Chinese (24.6\%) and Indian (7.3\%) (Department of Statistics Malaysia Official Portal). At recruitment, all participants $(n=3822)$ provided a blood or saliva sample and completed a detailed questionnaire that included lifestyle and reproductive-related factors for breast cancer as well as personal and family history of cancer. We excluded 46 related samples and 15 duplicated samples, resulting in 3761 patients included in the study of associations between PTV carriership and tumor characteristics. A subset of 3264 patients were eligible for survival analysis.

\section{The Korean Hereditary Breast Cancer Study (KOHBRA)}

The KOHBRA study is a prospective hereditary breast cancer cohort in Korea [10]. Between May 2007 and May 2010, the KOHBRA study recruited 1967 subjects from 35 hospitals registered in the Korean Breast Cancer Society. All participants received genetic counseling and $B R C A$ genetic testing; the clinical information and blood samples for blood banking were collected. Included in the study were patients with a family history of breast or ovarian cancers, patients with non-familial breast and ovarian cancer but with other risk factors of genetic disease, and family members of breast cancer patients with BRCA1/2 mutations [11]. Patients with information on PTVs $(n=562)$ were included in the study of associations between PTV carriership and tumor characteristics. The KOHBRA study was omitted from the survival analysis as it is a $B R C A 1 / 2$ case-control study oversampling $B R C A 1 / 2$ carriers, which will result in a survival bias in our PTV carriership analysis if included.

\section{Demographic information}

Self-reported ethnicity (Chinese, Malay, Indian, and others) and family history of breast cancer (yes, no) were obtained from structured questionnaires, in SGBCC and MyBrCa. All patients from KOHBRA were Koreans and family history was obtained from a structured questionnaire.

\section{Clinical data for breast cancer patients}

Clinical characteristics were extracted from hospital breast cancer registries or hospital medical records-age at diagnosis (years), tumor stage (0, I-IV), tumor size (< $2 \mathrm{~cm}, 2-5 \mathrm{~cm}$, and $>5 \mathrm{~cm}$, similar to TNM size reported by AJCC version 7), nodal status (positive, negative), tumor grade (well-differentiated, moderately differentiated, and poorly differentiated), and immunohistochemical markers ER, PR, and HER2. For ER status and PR status, staining of $\geq 1 \%$ was considered positive. HER2 status was classified as positive or negative (includes equivocal). Intrinsic-like subtypes were defined using immunohistochemical markers for ER, PR, and HER2 in conjunction with histologic grade: luminal $\mathrm{A}[\mathrm{ER}+/ \mathrm{PR}+$,
HER2-, well- or moderately differentiated], luminal B [HER2-] (ER+/PR+, HER2-, and poorly differentiated), luminal B [HER2+] (ER+/PR+, HER + , and poorly differentiated), HER2-enriched [HER2+], triple-negative [ER-, PR-, and HER2-] [12].

Treatment data, for SGBCC and MyBrCa, were extracted from hospital breast cancer registries or hospital medical records-surgery (yes, no), neo-adjuvant and/or adjuvant chemotherapy (yes, no), radiotherapy (yes, no), endocrine therapy (yes, no), and trastuzumab therapy (yes/no).

\section{Targeted sequencing}

DNA isolation was performed according to the manufacturer's instructions for buffy coat (FlexiGene DNA kit, Qiagen, or Promega's Maxwell 16 Blood DNA Purification Kit) in SGBCC and MyBrCa, and G-DEX(TM) II Genomic DNA extraction kit (Intron) in KOHBRA. DNA isolation for saliva samples (only in SGBCC) was performed using Oragene and prepIT $\cdot \mathrm{L} 2 \mathrm{P}$ reagent, DNA Genotek.

Target-enriched sequencing libraries of germline DNA for the breast cancer cases and controls were prepared at the Centre for Cancer Genetic Epidemiology (University of Cambridge) as part of a larger effort (Breast Cancer Risk after Diagnostic Gene Sequencing, BRIDGES, https://bridges-research.eu) [13]. The gene panel, which was developed as part of the BRIDGES initiative, included coding sequences and intron/exon boundaries for a total of 34 genes for which there was prior evidence of association with breast cancer risk, including genes offered on commercial panels for breast cancer in early 2016 (Additional file 1: Table S1). The targeted sequencing workgroup in BRIDGES first performed rare variant detection in preliminary gene panels combined with data from whole-exome sequencing datasets before arriving at the 34 genes selected for the BRIDGES panel. Details of the library preparation, sequencing, variant calling, and quality control methods are given in Dorling et al. [13].

\section{Protein-truncating variant (PTV) carriership}

In this study, PTVs were defined as (1) variants predicted to introduce a premature stop codon (frameshift or nonsense mutations), (2) small insertions or deletions (indels) predicted to disrupt a transcript's reading frame, or (3) splice site mutations. PTVs occurring in the last exon of each gene were excluded to avoid including variants that do not lead to nonsense-mediated decay. Variants with less than $1 \%$ frequency in our study population were included. A list of PTVs from the 34 genes sequenced is listed in Additional file 1: Table S2. The distribution of PTVs in unselected breast cancer patients from SGBCC and MyBrCa was visualized in oncoplot 
and bar chart (Additional file 1: Fig. S1). As the PTVs are rare [14], the number of carriers in most genes was too small to analyze individually. Hence, we aggregated PTVs for each individual, creating a single binary variable: carrier of at least one PTV in any gene versus non-carrier. We hypothesized that the effects of PTVs on subtype and outcome were likely to be in the same direction and therefore the power to detect an association with this burden variable would be much greater.

\section{Statistical analysis}

Fisher's exact test was used to determine whether the proportion of PTV carriers for individual genes was different between two of the largest ethnic subgroups in this study (i.e., Chinese and Malay). To test for associations between PTV carriership and tumor characteristics in the full analytical cohort of 8852 breast cancer patients, we carried out multinomial logistic regression models (multinom function in the $\mathrm{R}$ package "nnet") with tumor characteristics as the outcome, adjusting for age at diagnosis, study, and ethnicity. Odds ratios (ORs) and corresponding 95\% confidence intervals (CIs) were estimated. While SGBCC and MyBrCa included three core ethnic groups, KOHBRA consisted of a homogeneous population of Koreans; hence, adjustment for study and ethnicity was done as a joint variable.

Overall survival was studied in a subset of patients $(n$ $=6477,73 \%$ of analytical cohort, KOHBRA study excluded). Additional file 1: Fig. S2 and Fig. S3 show the Kaplan-Meier curves including and excluding KOHBRA patients, respectively. Other exclusions made are as follows: (1) unknown age at diagnosis or age 75 and above at diagnosis $[n=240],(2)$ stage $0[n=711]$ or stage IV [ $n=262]$ disease, (3) unknown recruitment or follow-up date $[n=10]$, and (4) patients with time at entry after the follow-up time of 10 years $[n=590]$. Time at entry was defined as the time between the date of recruitment and the date of diagnosis. Follow-up time was defined as the time between the date of death/last known alive date and the diagnosis date, truncated at 10 years postdiagnosis.

Overall survival was studied using Cox proportional hazard models (survival package in R, where the Surv(time at entry, follow-up time, event)) command was used to estimate hazard ratios (HRs) and corresponding 95\% CI. Adjustment for age at diagnosis, study (SGBCC, $\mathrm{MyBrCa}$ ), ethnicity (Chinese, Malay, Indian, others), and tumor characteristics (stage, grade, ER status, nodal status, and tumor size) was done. As age 50 years is a common recommendation to start mammography screening, the survival analysis was repeated for subgroups of patients diagnosed at different age groups $(<50$ years and 50-75 years). A test for interaction (likelihood ratio test) between PTV and age group was performed using Cox proportional hazard models which included the following variables: PTV carriership, age group $(<50,50$ to 75$)$, study, ethnicity, and tumor characteristics.

\section{PTV gene subset analysis}

In the recent study by Dorling et al. [13] involving 60,466 female breast cancer cases and 53,461 controls from 44 studies, PTVs in nine of the 34 genes (ATM, BRCA1, BRCA2, CHEK2, PALB2, BARD1, RAD51C, $R A D 51 D$, and TP53) were found to be strongly associated with breast cancer risk (Bayesian false-discovery probability, <0.05). Association and survival analyses were repeated for PTV carriership coded for these nine genes and separately for the remaining 25 genes. In the analysis of the remaining 25 genes, carriers of any of the nine genes associated with breast cancer risk were excluded.

\section{PTV subset analysis}

As $B R C A 1 / 2$ carriers tend to be associated with more aggressive tumor characteristics [15], all analyses were repeated without $B R C A 1 / 2$ carriers to assess the combined effect of other breast cancer predisposition genes.

Intrinsic breast tumor subtypes are known to be highly predictive with breast cancer survival [16]. In addition, heterogeneity has been observed for breast cancer susceptibility risk genes across clinical subtypes for breast cancer $[13,17]$. Hence, we performed further analysis to study the association of PTV carriership with tumor characteristics and survival was within each proxy subtype (luminal A, luminal B [HER2-], luminal B [HER2+ ], HER2-enriched [HER2+], and triple-negative).

As ethnic Chinese breast cancer patients comprise the majority of the study population (71\%), all analyses were repeated on a subset of 6265 Chinese breast cancer patients.

All statistical analyses were performed using $\mathrm{R}$ version 4.0.2.

\section{Results}

\section{Characteristics of the breast cancer cohorts}

Table 1 summarizes the characteristics of the 8852 breast cancer patients included in this study. The median age at diagnosis was 51 years (interquartile range $[I Q R] 44$ to 59$)$. Incident cases made up $59 \%$ of all the breast cancer patients. The majority of the patients were Chinese (71\%), followed by Malay (14\%), Indian (8\%), and Korean (6\%). Fourteen percent of the patients reported having a family history of breast cancer. Additional file 1: Table S3 presents the characteristics of patients by study cohort. 
Table 1 Characteristics of breast cancer patients. IQR interquartile range

\begin{tabular}{ll}
\hline & $\boldsymbol{N}(\%)$ \\
\hline $\begin{array}{l}\text { Demographics } \\
\text { Study }\end{array}$ \\
SGBCC \\
MyBrCa & $4529(51 \%)$ \\
KOHBRA & $3761(42 \%)$ \\
\end{tabular}

\section{Case type \\ Incident \\ Prevalent \\ Unknown}

Median age at diagnosis (IQR)

Unknown

Ethnicity
Chinese
Malay
Indian
Korean
Others
Unknown
Family history
No
Yes
Unknown

\section{Tumor characteristics}

Tumor behavior

In situ

Invasive

Unknown

Stage

0

।

॥

III

IV

Unknown

Nodal status

Negative

Positive

Unknown

Tumor size, cm

$\leq 2$

$2-5$

$>5$

Unknown

$4765(54 \%)$

2889 (33\%)

$1198(14 \%)$

$1171(13 \%)$

1837 (21\%)

3916 (44\%)

1928 (22\%)
Table 1 Characteristics of breast cancer patients. IQR interquartile range (Continued)

\begin{tabular}{|c|c|}
\hline & $N(\%)$ \\
\hline \multicolumn{2}{|l|}{ Grade } \\
\hline Well-differentiated & $1029(12 \%)$ \\
\hline Moderately differentiated & $3284(37 \%)$ \\
\hline Poorly differentiated & $3038(34 \%)$ \\
\hline Unknown & $1501(17 \%)$ \\
\hline \multicolumn{2}{|l|}{ Estrogen receptor status } \\
\hline Positive & $5542(63 \%)$ \\
\hline Negative & $2242(25 \%)$ \\
\hline Unknown & $1068(12 \%)$ \\
\hline \multicolumn{2}{|l|}{ Progesterone receptor status } \\
\hline Positive & $4722(53 \%)$ \\
\hline Negative & $2820(32 \%)$ \\
\hline Unknown & $1310(15 \%)$ \\
\hline \multicolumn{2}{|l|}{ HER2 receptor status } \\
\hline Positive & $1894(21 \%)$ \\
\hline Negative & $4645(52 \%)$ \\
\hline Unknown & $2313(26 \%)$ \\
\hline \multicolumn{2}{|l|}{ Proxy subtype } \\
\hline Luminal A & $2448(28 \%)$ \\
\hline Luminal B [HER2-] & 837 (9\%) \\
\hline Luminal B [HER2+] & $1033(12 \%)$ \\
\hline HER2-overexpressed & 757 (9\%) \\
\hline Triple-negative & $914(10 \%)$ \\
\hline Unknown & $2863(32 \%)$ \\
\hline \multicolumn{2}{|c|}{ Protein-truncating variants (PTVs) } \\
\hline \multicolumn{2}{|l|}{ PTV 34 genes } \\
\hline Non-carrier & $7873(89 \%)$ \\
\hline Carrier & $979(11 \%)$ \\
\hline \multicolumn{2}{|l|}{ PTV 9 genes } \\
\hline Non-carrier & $8162(92 \%)$ \\
\hline Carrier & $690(8 \%)$ \\
\hline \multicolumn{2}{|l|}{ PTV 25 genes } \\
\hline Non-carrier & $8524(96 \%)$ \\
\hline Carrier & $328(4 \%)$ \\
\hline
\end{tabular}

PTV-associated tumors were phenotypically more aggressive

Approximately $11 \%$ of breast cancer patients (979 carriers) carried at least one PTV among the 34 genes sequenced (prevalence of $8 \%$ in Chinese, 9\% in Malay, $9 \%$ in Indian, and $50 \%$ in Korean [KOHBRA was enriched for $B R C A 1 / 2$ carriers]) (Table 1). The proportion of PTV carriers in four genes were significantly different between Chinese and Malay breast cancer patients (Fisher's exact test, BRCA1, $p=0.009$; 
BRCA2, $p=0.008 ;$ MUTYH, $p=2.65 \mathrm{E}-4 ;$ MSH6, $p=$ 0.003 , Additional file 1: Table S4). The proportion of BRCA1 carriers were approximately twofold higher in Malay breast cancer patients compared to Chinese breast cancer patients. MUTYH PTVs were more common in Malay patients while MSH6 PTVs were more common in Chinese patients. However, multiple testing for 34 genes needs to be considered when interpreting these results.

Compared to tumors in breast cancer patients without any predicted $\mathrm{PTV}_{34 \text { genes }}$ (adjusted for age at diagnosis, study, and ethnicity), tumors of $\mathrm{PTV}_{34 \mathrm{genes}}$ carriers were more likely to be of advanced stage $\left(O R_{\text {stage }}\right.$ II vs stage I 1.34 [1.10 to 1.63 ], $O R_{\text {stage III vs stage I }} 1.29$ [1.00 to 1.66 ]), more likely to be invasive (vs in situ, OR 1.48 [1.15 to 1.91]), node-positive (vs node-negative, $O R 1.28$ [1.10 to 1.49]), higher grade (poorly vs well-differentiated, $O R$ 1.64 [1.26 to 2.14]), larger $\left(O R_{>5}\right.$ vs $<2 \mathrm{~cm} 1.47$ [1.11 to 1.93], $O R_{2-5}$ vs $\leq 2 \mathrm{~cm} 1.39$ [1.09 to 1.77]), ER-negative (vs ER-positive, OR 1.40 [1.19 to 1.64]), PR-negative (vs PRpositive, OR 1.40 [1.20 to 1.64]), and HER2-negative (vs HER2-positive, 1.42 [1.17 to 1.73]) (Table 2). In addition, PTV-associated tumors were more often of luminal B [HER2-] (vs luminal A, OR 1.68 [1.30 to 2.18]) and triple-negative subtypes (vs luminal A, OR 2.22 [1.76 to 2.80]). After the exclusion of 522 BRCA1/2 carriers, stage $\left(O R_{\text {stage II vs stage I }} 1.33\right.$ [1.03 to 1.72$\left.]\right)$, tumor size $\left(O R_{2-5 \mathrm{~cm}}\right.$ vs $\leq 2 \mathrm{~cm} 1.92$ [1.33 to 2.77]), and subtype $\left(O R_{\text {luminal B }}\right.$ [HER2-] vs luminal A 1.46 [1.04 to 2.05]) remained significantly associated with $\mathrm{PTV}_{34 \text { genes }}$ carriership (Table 2).

Compared to $\mathrm{PTV}_{34 \text { genes }}$ carriership, the observed associations with tumor characteristics were generally larger in effect size when $\mathrm{PTV}_{\text {ggenes }}$ carriership (i.e., nine genes found to be significant in Dorling et al. [18]) was evaluated (Table 3). After the omission of BRCA1/2 carriers from the analysis, stage $\left(O R_{\text {stage II vs stage I }}[95 \% C I]\right.$ 1.86 [1.20 to 2.87]), grade $\left(O R_{\text {poorly vs well-differentiated }}\right.$ [95\% Cl] 3.67 [1.77 to 7.62$])$, size $\left(O R_{>5 \mathrm{~cm}}\right.$ vs $\leq 2 \mathrm{~cm} 2.03$ [1.02 to 4.04]), and subtype $\left(O R_{\text {luminal B [HER2-] vs luminal A }}\right.$ 2.37 [1.44 to 3.91] and $O R_{\text {triple-negative vs luminal A } 1.90}$ [1.12 to 3.23]) remained significantly associated with PTV $_{\text {ggenes }}$ carriership (Table 3).

Similar to $\mathrm{PTV}_{\text {ggenes }}$ carriership after the exclusion of BRCA1/2 carriers, $\mathrm{PTV}_{25 \text { genes }}$ carriership of the remaining 25 genes was not significantly associated with most tumor characteristics, with the exception of tumor

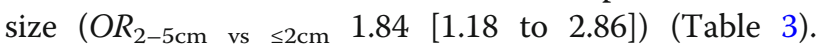
Grade was also significantly associated with $\mathrm{PTV}_{25 \text { genes }}$ carriership, but in the opposite direction grade $\left(O R_{\text {mode- }}\right.$


$O R_{\text {poorly vs well-differentiated }}$ [95\% CI] 0.69 [0.48 to 0.97$]$ ).

We further conducted subset analyses to evaluate the relationship between PTV carriership and tumor characteristics within subgroups of patients with breast cancers of different proxy subtypes (Table S5). Among patients of luminal A subtype, $\mathrm{PTV}_{34 \text { genes }}$ and $\mathrm{PTV}_{9 \mathrm{genes}}$ carriership were associated with stage $\left(p_{\text {cumulative logistic }}\right.$ regression $=0.010$ and 0.008 , respectively) and nodal status $\left(O R_{\text {positive vs negative }} 1.79\right.$ [1.31 to 2.45$]$ and 1.95 [1.30 to 2.92], respectively). Among patients of luminal B [HER2+] subtype, $\mathrm{PTV}_{34 \text { genes }}$ and $\mathrm{PTV}_{\text {9genes }}$ carriership were associated with tumor size ( $p_{\text {cumulative logistic regression }}$ $=0.013$ and 0.008 , respectively).

\section{PTV carriership and overall survival within 10 years post- diagnosis}

In 6477 invasive non-metastatic breast cancer patients aged $<75$ years at diagnosis from SGBCC and MyBrCa, a total of 790 deaths due to any cause occurred within 10 years after diagnosis with a median follow-up time of $\sim 5.6$ years (IQR 3.4 to 8.5 ). The 10-year overall survival rate was $75 \%$ (95\% CI 74 to $77 \%$ ). In these 6477 patients, associations between PTV carriership and tumor characteristics were found to be similar with those from the entire analytical cohort of 8852 patients (Additional file 1: Table S6). Population structure of the major ethnic groups in SGBCC and $\mathrm{MyBrCa}$ was largely similar; Additional file 1: Fig. S4 shows a principal component analysis plot of SGBCC and $\mathrm{MyBrCa}$ breast cancer patients, colored by study (SGBCC or MyBrCa) and denoted by ethnicity (Chinese, Malay, or Indian).

PTV $_{34 \text { genes }}$ was not found to be associated with 10year overall survival (Additional file 1: Table S7, Fig. S5). The results were not appreciably different after adjustment for age at diagnosis, study, ethnicity, stage, grade, ER status, nodal status, and tumor size or when BRCA1/ 2 carriers were excluded (Additional file 1: Table S7, Table 4, and Additional file 1: Fig. S6).

PTV $_{\text {ggenes }}$ carriership was not significantly associated with 10-year overall survival (Additional file 1: Table S7 and Fig. S7). After adjusting for age at diagnosis, study, ethnicity, stage, grade, ER status, nodal status, and tumor size, $\mathrm{PTV}_{\text {9genes }}$ carriership (HR 0.54 [0.32 to 0.92]) was associated with better overall survival in older breast cancer patients (50 to 75 years) (Table 4). Among younger patients, the $H R(95 \% C I)$ was 0.92 (0.63 to 1.34 ) ( $p$ $=0.654)$. The protective effect among older patients remained significant when only $B R C A 1 / 2$ PTVs were considered in the gene subset (HR 0.42 [0.19 to 0.94], $p$ $=0.035)$.

In contrast, $\mathrm{PTV}_{25 \text { genes }}$ carriership was significantly associated with 10-year overall survival in the analysis including breast cancer patients of any age (adjusted $H R$ 1.63 [1.16 to 2.28], Table 4). The effect size was larger for older breast cancer patients (adjusted HR 1.77 [1.13 to 2.79]) compared to younger patients (adjusted $H R$ 1.48 [0.89 to 2.46], $p=0.131$, Table 4 and Additional file 
Table 2 Associations between protein-truncating variant [PTV] carriership (34 genes) and demographics, and tumor characteristics

\begin{tabular}{|c|c|c|c|c|c|c|c|c|}
\hline \multirow{2}{*}{ 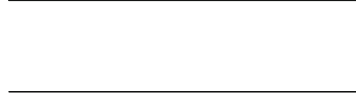 } & \multicolumn{4}{|c|}{ (i) PTV 34 genes } & \multicolumn{4}{|c|}{ (ii) PTV 34 genes-excluding BRCA1/2 carriers } \\
\hline & Non-carrier & Carrier & OR $(95 \% \mathrm{Cl})$ & $p$ & Non-carrier & Carrier & OR $(95 \% C l)$ & $p$ \\
\hline \multicolumn{9}{|l|}{ Demographics } \\
\hline \multicolumn{9}{|l|}{ Family history } \\
\hline No & 6437 & 531 & 1.00 (reference) & & 6437 & 346 & 1.00 (reference) & \\
\hline Yes & 1061 & 159 & 1.89 (1.56 to 2.29$)$ & $<0.001$ & 1061 & 81 & $1.43(1.12$ to 1.84$)$ & 0.005 \\
\hline Unknown & 375 & 289 & 2.08 (1.27 to 3.41$)$ & 0.004 & 375 & 30 & 1.26 (0.61 to 2.58$)$ & 0.531 \\
\hline \multicolumn{9}{|c|}{ Age group (adjusted for ethnicity and study) } \\
\hline$\geq 50$ & 4453 & 389 & 1.00 (reference) & & 4453 & 245 & 1.00 (reference) & \\
\hline$<50$ & 3394 & 586 & 1.36 (1.17 to 1.58$)$ & $<0.001$ & 3394 & 209 & 1.09 (0.90 to 1.32$)$ & 0.384 \\
\hline Missing age & 26 & 4 & 2.61 (0.84 to 8.06) & 0.096 & 26 & 3 & 3.23 (0.88 to 11.83 ) & 0.077 \\
\hline \multicolumn{9}{|c|}{ Ethnicity (adjusted for age at diagnosis only) } \\
\hline Chinese (MyBrCa) & 2361 & 227 & 1.00 (reference) & & 2361 & 142 & 1.00 (reference) & \\
\hline Chinese (SGBCC) & 3390 & 287 & $0.91(0.76$ to 1.10$)$ & 0.341 & 3390 & 202 & $1.01(0.81$ to 1.26$)$ & 0.955 \\
\hline Malay (MyBrCa) & 556 & 63 & 1.07 (0.79 to 1.44$)$ & 0.676 & 556 & 25 & $0.71(0.45$ to 1.10$)$ & 0.124 \\
\hline Malay (SGBCC) & 542 & 52 & 1.00 (0.73 to 1.37$)$ & 0.989 & 542 & 31 & 0.95 (0.64 to 1.42 ) & 0.818 \\
\hline Indian (MyBrCa) & 404 & 48 & 1.25 (0.90 to 1.74$)$ & 0.185 & 404 & 26 & 1.08 (0.70 to 1.66$)$ & 0.729 \\
\hline Indian (SGBCC) & 238 & 17 & 0.78 (0.47 to 1.30$)$ & 0.338 & 238 & 4 & 0.28 (0.10 to 0.78$)$ & 0.014 \\
\hline Korean & 282 & 280 & 8.38 (6.68 to 10.50$)$ & $<0.001$ & 282 & 24 & 1.28 (0.80 to 2.04 ) & 0.308 \\
\hline Others/unknown & 100 & 5 & 0.51 (0.18 to 1.39$)$ & 0.187 & 100 & 3 & 0.40 (0.10 to 1.63$)$ & 0.199 \\
\hline \multicolumn{9}{|l|}{ Tumor characteristics } \\
\hline \multicolumn{9}{|l|}{ Stage } \\
\hline 0 & 703 & 56 & 0.83 (0.60 to 1.14$)$ & 0.247 & 703 & 34 & 0.96 (0.64 to 1.43 ) & 0.822 \\
\hline । & 2038 & 206 & 1.00 (reference) & & 2038 & 103 & 1.00 (reference) & \\
\hline$\|$ & 2421 & 325 & 1.34 (1.10 to 1.63$)$ & 0.003 & 2421 & 161 & 1.33 (1.03 to 1.72$)$ & 0.028 \\
\hline III & 1007 & 116 & 1.29 (1.00 to 1.66$)$ & 0.047 & 1007 & 61 & 1.23 (0.89 to 1.70$)$ & 0.216 \\
\hline IV & 240 & 30 & 1.49 (0.98 to 2.26) & 0.064 & 240 & 11 & $0.96(0.50$ to 1.81$)$ & 0.889 \\
\hline Unknown & 1464 & 246 & 1.30 (1.05 to 1.61$)$ & 0.015 & 1464 & 87 & 1.14 (0.85 to 1.54$)$ & 0.379 \\
\hline Cumulative logistic model & 6409 & 733 & 1.32 (1.14 to 1.52 ) & $<0.001$ & 6409 & 370 & 1.18 (0.98 to 1.42 ) & 0.090 \\
\hline \multicolumn{9}{|l|}{ Tumor behavior } \\
\hline In situ & 949 & 79 & 1.00 (reference) & & 949 & 43 & 1.00 (reference) & \\
\hline Invasive & 6628 & 850 & 1.48 (1.15 to 1.91$)$ & 0.003 & 6628 & 401 & 1.35 (0.97 to 1.87 ) & 0.073 \\
\hline Unknown & 296 & 50 & 1.13 (0.74 to 1.72 ) & 0.583 & 296 & 13 & 0.74 (0.36 to 1.50$)$ & 0.401 \\
\hline \multicolumn{9}{|l|}{ Nodal status } \\
\hline Negative & 4282 & 483 & 1.00 (reference) & & 4282 & 240 & 1.00 (reference) & \\
\hline Positive & 2519 & 370 & 1.28 (1.10 to 1.49$)$ & 0.002 & 2519 & 168 & $1.20(0.98$ to 1.47$)$ & 0.081 \\
\hline Unknown & 1072 & 126 & $0.89(0.71$ to 1.11$)$ & 0.290 & 1072 & 49 & 0.78 (0.56 to 1.07 ) & 0.127 \\
\hline \multicolumn{9}{|l|}{ Grade } \\
\hline Well-differentiated & 947 & 82 & 1.00 (reference) & & 947 & 58 & 1.00 (reference) & \\
\hline Moderately differentiated & 2980 & 304 & 1.23 (0.94 to 1.61$)$ & 0.131 & 2980 & 154 & 0.85 (0.62 to 1.16$)$ & 0.311 \\
\hline Poorly differentiated & 2672 & 366 & 1.64 (1.26 to 2.14$)$ & $<0.001$ & 2672 & 177 & 1.09 (0.80 to 1.48$)$ & 0.577 \\
\hline Unknown & 1274 & 227 & 1.25 (0.94 to 1.68$)$ & 0.124 & 1274 & 68 & 0.81 (0.56 to 1.18 ) & 0.272 \\
\hline Cumulative logistic model & 6599 & 752 & 1.41 (1.21 to 1.64$)$ & $<0.001$ & 6599 & 389 & $1.16(0.95$ to 1.41$)$ & 0.140 \\
\hline
\end{tabular}


Table 2 Associations between protein-truncating variant [PTV] carriership (34 genes) and demographics, and tumor characteristics (Continued)

\begin{tabular}{|c|c|c|c|c|c|c|c|c|}
\hline & \multicolumn{4}{|c|}{ (i) PTV 34 genes } & \multicolumn{4}{|c|}{ (ii) PTV 34 genes-excluding BRCA1/2 carriers } \\
\hline & Non-carrier & Carrier & OR $(95 \% \mathrm{Cl})$ & $p$ & Non-carrier & Carrier & OR $(95 \% \mathrm{Cl})$ & $p$ \\
\hline \multicolumn{9}{|l|}{ Tumor size, $\mathrm{cm}$} \\
\hline$\leq 2$ & 1019 & 152 & 1.00 (reference) & & 1019 & 41 & 1.00 (reference) & \\
\hline $2-5$ & 1599 & 238 & 1.39 (1.09 to 1.77$)$ & 0.007 & 1599 & 119 & $1.92(1.33$ to 2.77$)$ & $<0.001$ \\
\hline$>5$ & 3582 & 334 & $1.47(1.11$ to 1.93$)$ & 0.007 & 3582 & 205 & 1.48 (0.98 to 2.23$)$ & 0.060 \\
\hline Unknown & 1673 & 255 & $1.36(1.06$ to 1.74$)$ & 0.014 & 1673 & 92 & 1.38 (0.93 to 2.05$)$ & 0.108 \\
\hline Cumulative logistic model & 6200 & 724 & 1.24 (1.02 to 1.50$)$ & 0.030 & 6200 & 365 & $1.20(0.92$ to 1.55$)$ & 0.177 \\
\hline \multicolumn{9}{|l|}{ Estrogen receptor status } \\
\hline Positive & 5034 & 508 & 1.00 (reference) & & 5034 & 283 & 1.00 (reference) & \\
\hline Negative & 1933 & 309 & 1.40 (1.19 to 1.64$)$ & $<0.001$ & 1933 & 121 & 1.11 (0.89 to 1.38$)$ & 0.368 \\
\hline Unknown & 906 & 162 & $1.20(0.97$ to 1.49$)$ & 0.092 & 906 & 53 & 0.96 (0.70 to 1.31$)$ & 0.786 \\
\hline \multicolumn{9}{|c|}{ Progesterone receptor status } \\
\hline Positive & 4296 & 426 & 1.00 (reference) & & 4296 & 232 & 1.00 (reference) & \\
\hline Negative & 2461 & 359 & 1.40 (1.20 to 1.64$)$ & $<0.001$ & 2461 & 149 & $1.13(0.91$ to 1.40$)$ & 0.257 \\
\hline Unknown & 1116 & 194 & 1.33 (1.09 to 1.62$)$ & 0.005 & 1116 & 76 & $1.20(0.91$ to 1.57$)$ & 0.200 \\
\hline \multicolumn{9}{|l|}{ HER2 receptor status } \\
\hline Positive & 1735 & 159 & 1.00 (reference) & & 1735 & 108 & 1.00 (reference) & \\
\hline Negative & 4061 & 584 & 1.42 (1.17 to 1.73$)$ & $<0.001$ & 4061 & 235 & 0.93 (0.73 to 1.18 ) & 0.537 \\
\hline Unknown & 2077 & 236 & 1.12 (0.90 to 1.40$)$ & 0.302 & 2077 & 114 & 0.85 (0.65 to 1.12 ) & 0.254 \\
\hline \multicolumn{9}{|l|}{ Proxy subtype } \\
\hline Luminal A & 2244 & 204 & 1.00 (reference) & & 2244 & 113 & 1.00 (reference) & \\
\hline Luminal B [HER2-] & 729 & 108 & 1.68 (1.30 to 2.18 ) & $<0.001$ & 729 & 52 & 1.46 (1.04 to 2.05 ) & 0.029 \\
\hline Luminal B [HER2+] & 947 & 86 & 0.97 (0.74 to 1.27$)$ & 0.823 & 947 & 59 & 1.24 (0.90 to 1.72 ) & 0.196 \\
\hline HER2-overexpressed & 705 & 52 & 0.83 (0.60 to 1.15$)$ & 0.272 & 705 & 36 & 1.02 (0.69 to 1.50$)$ & 0.912 \\
\hline Triple-negative & 727 & 187 & 2.22 (1.76 to 2.80$)$ & $<0.001$ & 727 & 51 & 1.38 (0.98 to 1.95$)$ & 0.065 \\
\hline Unknown & 2521 & 342 & 1.20 (0.98 to 1.45$)$ & 0.072 & 2521 & 146 & 1.12 (0.86 to 1.44$)$ & 0.400 \\
\hline
\end{tabular}

Models are adjusted for age at diagnosis (years) and the joint variable of study and ethnicity. Odds ratios (ORs) and $95 \%$ confidence intervals (Cls) were estimated using multinomial logistic regression models with each tumor characteristic as the outcome and genetic factors as explanatory variables; patients with unknown values were excluded from the analysis. $p$-value from Wald test. Results associated with $p<0.05$ are denoted in bold

1: Fig. S8). The likelihood ratio tests (LRT) for interaction between PTV and age group $(<50$ years, 50 to 75 years) in the adjusted models (study, ethnicity, stage, grade, ER status, nodal status, and tumor size) were not statistically significant ( $p$-values, $\mathrm{PTV}_{34 \text { genes }} 0.507$, $\mathrm{PTV}_{\text {9genes }}$ 0.084, and $\mathrm{PTV}_{25 \text { genes }}$ 0.556). Further adjustments for treatment variables for all survival analyses did not appreciably change the results (Additional file 1: Table S9).

Kaplan-Meier curves for 10-year overall survival within each proxy subtype are presented in Additional file 1: Fig. S9 to S11. Significant associations were observed between $\mathrm{PTV}_{34 \text { genes }}$ and $\mathrm{PTV}_{25 \text { genes }}$ carriership and worse 10-year overall survival in the HER2-overexpressed proxy subtype. However, it should be noted that the results have to be interpreted with caution due to the limited number of death events within each subgroup.

\section{Subset analysis in Chinese breast cancer patients}

The results observed for Chinese breast cancer patients were similar to that of all breast cancer patients, for associations between PTV carriership and tumor characteristics and also associations between PTV carriership and survival. While the $p$-values were no longer statistically significant due to the reduced sample size comprising only Chinese breast cancer patients, the observed odds ratios and hazard ratios were not appreciably different. These results are presented in Additional file 1: Tables S9 and S10.

\section{Discussion}

Evaluating disease associations for rare variants in standard single-variant association analysis is challenging, since even if the effect size is large, the statistical power may still be low [19]. However, grouping variants in 


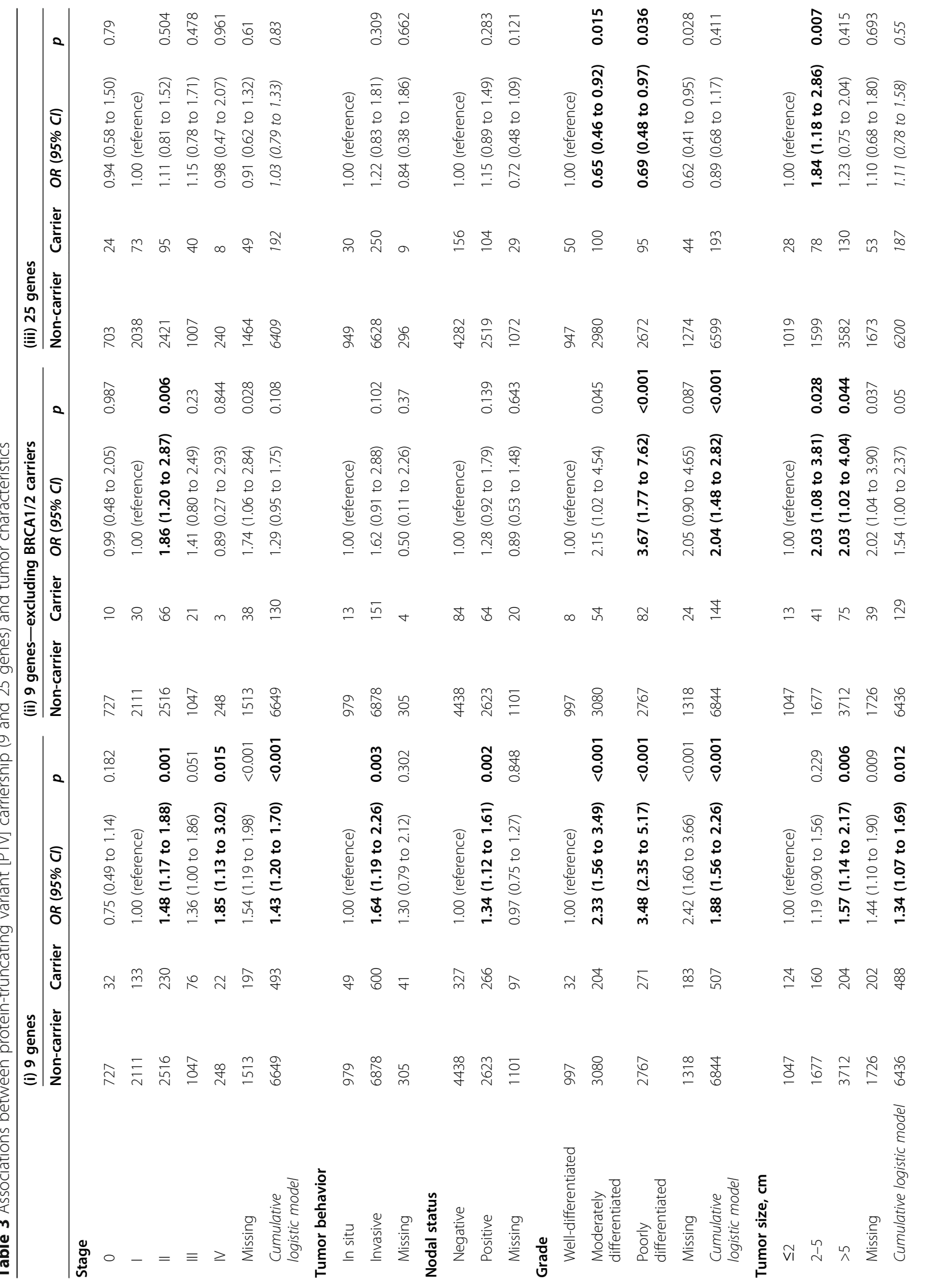




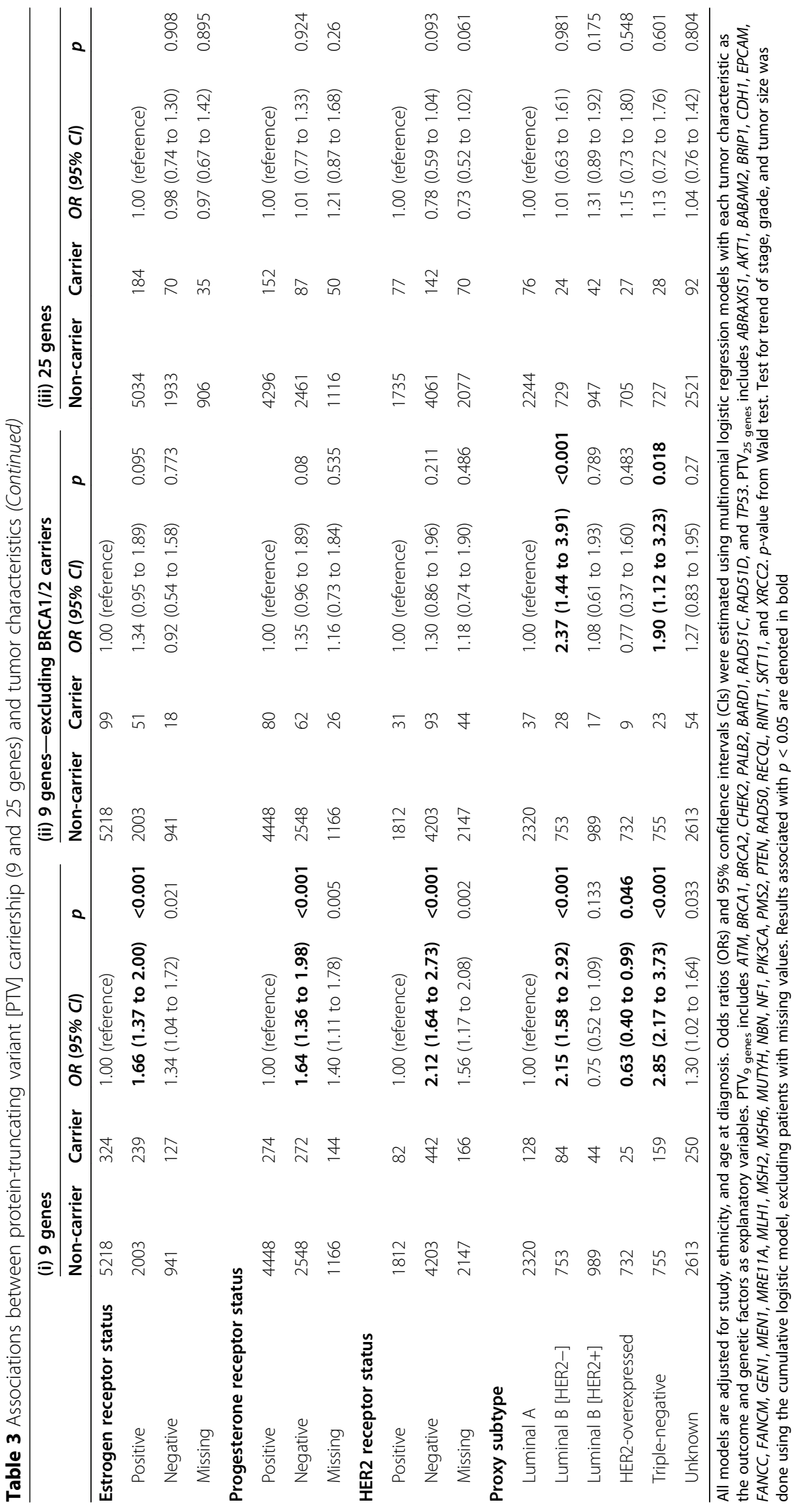


Table 4 Associations between protein-truncating variant [PTV] carriership (34, 9, 25 genes) and overall survival

\begin{tabular}{|c|c|c|c|c|c|c|c|c|c|c|c|c|}
\hline & \multicolumn{4}{|c|}{ (A) All ages } & \multicolumn{3}{|c|}{ (B) $<50$ years } & \multirow[b]{2}{*}{$p$} & \multicolumn{4}{|c|}{ (C) 50 to 75 years } \\
\hline & Alive & Dead & $H R(95 \% \mathrm{Cl})$ & $p$ & Alive & Dead & $H R(95 \% C l)$ & & Alive & Dead & $H R(95 \% \mathrm{Cl})$ & $p$ \\
\hline \multicolumn{13}{|c|}{ (i) PTV 34 genes } \\
\hline Non-carrier & 5213 & 710 & 1.00 (reference) & & 2152 & 308 & 1.00 (reference) & & 3061 & 402 & 1.00 (reference) & \\
\hline Carrier & 474 & 80 & $1.03(0.81$ to 1.29$)$ & 0.831 & 232 & 46 & 1.07 (0.78 to 1.46$)$ & 0.677 & 242 & 34 & $0.92(0.65$ to 1.31$)$ & 0.661 \\
\hline \multicolumn{13}{|c|}{ (ii) PTV 34 genes (excluding $B R C A 1 / 2$ carriers) } \\
\hline Non-carrier & 5213 & 710 & 1.00 (reference) & & 2152 & 308 & 1.00 (reference) & & 3061 & 402 & 1.00 (reference) & \\
\hline Carrier & 286 & 51 & 1.19 (0.89 to 1.58$)$ & 0.234 & 123 & 23 & 1.07 (0.69 to 1.64$)$ & 0.772 & 163 & 28 & 1.24 (0.84 to 1.82$)$ & 0.278 \\
\hline \multicolumn{13}{|l|}{ (i) PTV 9 genes } \\
\hline Non-carrier & 5386 & 746 & 1.00 (reference) & & 2229 & 324 & 1.00 (reference) & & 3157 & 422 & 1.00 (reference) & \\
\hline Carrier & 301 & 44 & $0.77(0.57$ to 1.05$)$ & 0.096 & 155 & 30 & 0.92 (0.63 to 1.34$)$ & 0.654 & 146 & 14 & $0.54(0.32$ to 0.92$)$ & 0.023 \\
\hline \multicolumn{13}{|c|}{ (ii) PTV 9 genes (excluding $B R C A 1 / 2$ carriers) } \\
\hline Non-carrier & 5386 & 746 & 1.00 (reference) & & 2229 & 324 & 1.00 (reference) & & 3157 & 422 & 1.00 (reference) & \\
\hline Carrier & 113 & 15 & 0.71 (0.42 to 1.18) & 0.183 & 46 & 7 & $0.64(0.30$ to 1.36$)$ & 0.241 & 67 & 8 & 0.69 (0.34 to 1.40$)$ & 0.309 \\
\hline \multicolumn{13}{|l|}{ (i) $B R C A 1 / 2$} \\
\hline Non-carrier & 5499 & 761 & 1.00 (reference) & & 2275 & 331 & 1.00 (reference) & & 3224 & 430 & 1.00 (reference) & \\
\hline Carrier & 188 & 29 & 0.82 (0.56 to 1.19$)$ & 0.289 & 109 & 23 & 1.06 (0.69 to 1.63$)$ & 0.780 & 79 & 6 & 0.42 (0.19 to 0.94$)$ & 0.035 \\
\hline \multicolumn{13}{|c|}{ (iii) PTV 25 genes (excluding carriers of PTV $_{9}$ genes) } \\
\hline Non-carrier & 5213 & 710 & 1.00 (reference) & & 2152 & 308 & 1.00 (reference) & & 3061 & 402 & 1.00 (reference) & \\
\hline Carrier & 173 & 36 & 1.63 (1.16 to 2.28$)$ & 0.004 & 77 & 16 & 1.48 (0.89 to 2.46$)$ & 0.131 & 96 & 20 & 1.77 (1.13 to 2.79$)$ & 0.013 \\
\hline
\end{tabular}

All Cox proportional hazard models are adjusted for age at diagnosis (years), study (SGBCC or MyBrCa), ethnicity (Chinese, Malay, Indian, or others), stage (I, II, or III), grade (well-, moderately, or poorly differentiated), estrogen receptor status (positive, negative), nodal status (positive, negative), and tumor size ( $\leq 2,2-5$, or $>5 \mathrm{~cm}$ ). (A) All ages and subgroups of (B) age at diagnosis $<50$ and (C) age at diagnosis 50 to 75 . Patients considered in each association studied are indicated as follows: (i) all breast cancer patients, (ii) excluding BRCA carriers, and (iii) excluding carriers of PTV ${ }_{9}$ genes $(A T M, B R C A 1, B R C A 2, C H E K 2, P A L B 2, B A R D 1, R A D 51 C$, RAD51D, and TP53). Hazard ratios (HRs) and corresponding 95\% confidence intervals (Cls) are shown. SD standard deviation

multimarker tests may substantially improve power [19]. For example, multiple common variants are frequently collapsed into a single polygenic risk score [20]. For rare variant analysis in a gene-based burden test, the number of individuals carrying variants in a given gene is compared between affected and unaffected groups [21]. While rare variant analyses are commonly carried out in a region or gene-based manner $[13,17]$, the collective effect of pathogenic variants across multiple breast cancer genes may also be studied $[6,22,23]$. In this large study of Asian breast cancer patients, we showed that PTV carriership in certain known or suggested breast cancer predisposition genes was associated with disease severity and fatality.

Two smaller studies on Asian Chinese breast cancer patients showed that while BRCA1/2 PTV carriers were associated with more aggressive clinical features, PTV carriers of non-BRCA1/2 breast cancer susceptibility genes when treated as a single group were not significantly associated with tumor characteristics (Wang et al., 480 patients, 65 PTV carriers for 20 genes [23]; Li et al., 936 patients, 223 PTV carriers for 40 genes [22]). However, in spite of differences in population ancestry, results from our large study of Asian breast cancer patients closely replicated the findings of a study comprising 5099 breast cancer patients of European descent [6]. The European study examined PTVs in 31 genes in an earlier version of the BRIDGES panel, of which 30 genes overlap with the 34 genes in our study. The overlap between the genes included in $\mathrm{Li}$ et al. [6] and the current study is shown in Additional file 1: Fig. S12. Li et al. [6] reported that compared to noncarriers, PTV carriers were more likely to have more aggressive tumors (i.e., ER-negative, large size, high grade, highly proliferative, luminal $\mathrm{B}$, and triplenegative subtype). We observed the same significant associations in our Asian study and additionally found significant associations between PTV carriership and disease stage, tumor behavior, nodal involvement, PR status, and HER2 status.

Taking into account the known associations between $B R C A 1 / 2$-related tumors and worse tumor biology, all analyses were repeated excluding BRCA1/2 carriers. $\mathrm{Li}$ et al. [6] observed that PTV carriership remained associated with high grade and worse survival. In our study, a significant association with grade was no longer seen after $B R C A 1 / 2$ carrier exclusion, but other tumor characteristics common of fast-growing tumors, such as stage, tumor size, and luminal B [HER2-] subtype, remained significant. 
A more recent study reported that not all of the 34 reported or known breast cancer susceptibility genes on the targeted sequencing panel were clinically relevant for the prediction of breast cancer risk [13]. The results of a subset analysis of the nine genes found to be associated with breast cancer risk suggest that the genes most relevant for breast cancer development were also associated with more aggressive tumor phenotypes (larger effect sizes observed than for 34 genes). Nonetheless, the worse tumor characteristics were mostly driven by $B R C A 1 / 2$ carriers-only stage, size, and subtype remained significantly associated with PTV carriership of the seven genes after the exclusion of BRCA1/2 carriers. PTV carriership of the remaining 25 genes was associated with a larger tumor size. What we found to be different from the Li et al. [6] Swedish study was that in our study, among BRCA1/2 non-carriers, there was a null relationship between PTV carriership (34 genes) and tumor grade. However, the gene subset analyses showed that while $\mathrm{PTV}_{\text {ggenes }}$ carriership predisposed patients to worse tumor grade, a larger proportion of PTV $_{\text {25genes }}$ carriers developed lower grade tumors.

We did not find a similar association between $\mathrm{PTV}_{34 \text { genes }}$ carriership and 10-year overall survival as reported in $\mathrm{Li}$ et al.'s work on a Swedish dataset of 5099 breast cancer patients [6]. Interestingly, the gene subset analyses showed that PTV carriership of the nine genes, found to be most relevant for breast cancer risk, did not appear to be associated with worse survival. In particular, $B R C A 1 / 2$ conferred a survival benefit for patients diagnosed above 50 years of age. PTV carriership of the remaining 25 genes, however, increased the risk of dying from any cause in all age groups. This observation is unexpected as while $\mathrm{PTV}_{\text {25genes }}$ carriership was associated with larger tumor size, the tumors were of a lower grade. A possible explanation could be that these 25 genes are associated with other cancers, for which we do not have information on to perform a competing risk analysis. An alternative explanation could be that some genes are important drivers of certain tumor subtypes associated with worse survival, which we do not have the statistical power to study. Further work in a larger study population, perhaps involving sub-analyses by further division of $\mathrm{PTV}_{25 \text { genes }}$ carriership, would be helpful in understanding this observation. Nonetheless, the results suggest that PTVs in breast cancer genes influence survival. Larger studies with higher statistical power will be needed to elucidate which of the genes are specifically associated with disease outcome.

The role of $B R C A 1 / 2$ in survival among breast cancer patients has been studied widely $[24,25]$. Most studies found that germline $B R C A 1 / 2$ carriers were at a higher risk of death than their BRCA-negative counterpart, but there are indications that triple-negative breast cancer patients who are $B R C A 1 / 2$ carriers have a better prognosis $[23,24,26]$. As $B R C A 1 / 2$ carriership has the potential to affect the efficacy of chemotherapy, the effect on survival will need to be interpreted in light of the standard of care and patient population studied [26].

Among South-East Asians, it has been observed that Malay breast cancer patients tend to develop more aggressive tumors and have poorer survival rates [27]. The survival difference has been attributed to ethnic differences in lifestyle, socio-economic status, cultural values, tumor biology, and response to treatment [27]. In a previous study comparing Chinese and Malay breast cancer patients, a higher prevalence of $B R C A 2$ mutations was found among Malay breast cancer patients [28]. Our larger study supports this finding and found significant differences in the prevalence of some breast cancer genes (BRCA1, MSH6, and $M U T Y H)$ between the two ethnic groups, suggesting that germline genetics may impact ethnic differences in breast cancer tumor characteristics and survival. However, a larger study is needed to validate these ethnic differences.

There are limitations to this study. Although this study is the largest to date to examine the impact of rare variants on breast cancer tumor characteristics and survival among patients of Asian ancestry, the number of carriers is still too limited for individual gene evaluation. The numbers are also too small to make definitive conclusions in specific ethnic subgroups. The effect of large germline structural variants (e.g., deletions, duplications, insertions, inversions, and translocations), which are not limited to genetic changes in coding regions, was not evaluated in this study [29]. Such variants have been documented to contribute to $10-25 \%$ of pathogenic variants for hereditary disorders [29]. However, germline structural variants are less frequent in breast cancer genes such as BRCA1 (0.8 to 6.9\%) and BRCA2 (5\%) in Asian populations [30, 31]. As only germline variants were studied, we were not able to evaluate somatic second hits in tumors leading to the biallelic inactivation of the breast cancer genes. In view of potential bias, differences in the study design of each included cohort and how representative they are of the breast cancer demographics in general must be considered. For example, oversampling of $B R C A 1 / 2$ carriers in the KOHBRA study could have led to bias in the estimates, but limiting the analyses to two hospital-based cohorts (SGBCC and $\mathrm{MyBrCa}$, unselected breast cancer patients) showed no evidence of such bias. Finally, we were not able to consider breast cancer-specific survival as the data was not consistently ascertained across all the studies. 
However, it is noteworthy that this large Asian breast cancer population studied is novel and timely in view of possible Eurocentric biases in genetic studies [7, 32].

\section{Conclusions}

It is important to identify germline carriers of high-risk breast cancer PTVs to prioritize individuals for inclusion in cancer surveillance programs, which has the potential to save lives [33, 34]. The finding that PTV carriership is not just associated with higher breast cancer risk, but also more severe and fatal forms of the disease, suggests that genetic testing has the potential to provide additional health information and help healthy individuals make screening decisions.

\section{Abbreviations \\ Cl: Confidence interval; ER: Estrogen receptor; HER2: Human epidermal growth factor receptor; HR: Hazard ratio; KOHBRA: Korean Hereditary Breast Cancer Study; MyBrCa: Malaysian Breast Cancer Genetic Study; OR: Odds ratio; PR: Progesterone receptor; PTV: Protein-truncating variant; SGBCC: Singapore Breast Cancer Cohort}

\section{Supplementary Information}

The online version contains supplementary material available at https://doi. org/10.1186/s13073-021-00978-9.

Additional file 1. Supplementary tables and figures. Description: This file contains Tables S1 to S10 and Fig. S1 to S12.

\section{Acknowledgements}

The study was made possible with the corporation of the participants and the assistance of research team members: from SGBCC — Jenny Liu, Siew Li Tan, Siok Hoon Yeo, Ting Ting Koh, Amanda Ong, Michelle Jia Qi Mo, Ying Jia Chew, Jin Yee Lee, Jing Jing Hong, Hui Min Lau, Ganga Devi D/O Chandrasegran, Nur Khaliesah Binte Mohamed Ri, Nayli Nur Hannah Binte Mazlan, and Zi Lin Lim, and from the UMMC Breast Cancer Research Group-Mee Hoong See, Tania Islam, Mei Sze Teh, and Li Ying Teoh.

\section{Authors' contributions}

Study design: $J \mathrm{~L}, \mathrm{MH}$, and $\mathrm{PJH}$; writing group: JL, PJH, MH, SHT, WKH, DFE, MKS, VKMT, BKTT, and FYW; data management: PJH, JL, AJK, MCT, EAW, AMD, DFE, and MKS; statistical analysis: PJH, JL, WKH, and MKS; provided DNA samples and phenotypic data: MH, VKMT, BKTT, SMT, YET, SHL, SHT, CHY, NAT, SJ, YS, FYW, JN, SCL, CWC, SAB, PMYC, JJCC, JCMS, WPL, CWM, GHL, EW, SWK, JWL, MHL, and SKP. All authors read and approved the final manuscript.

\section{Funding}

The sequencing and analysis for this project were funded by the European Union's Horizon 2020 Research and Innovation Programme (BRIDGES: grant number 634935) and the Wellcome Trust [grant no: v203477/Z/16/Z]. SGBCC was supported by the National Research Foundation Singapore [NRF-NRFF2017-02, awarded to J Li], NUS start-up Grant [awarded to $\mathrm{MH}$ ], National University Cancer Institute Singapore (NCIS) Centre Grant [NMRC/CG/NCIS/2010, NMRC/CG/012/2013 and CGAug16M005, awarded to MH], Breast Cancer Prevention Programme (BCPP, awarded to $\mathrm{MH}$ ), Asian Breast Cancer Research Fund [awarded to $\mathrm{MH}$ ], and the NMRC Clinician Scientist Award (SI Category) [NMRC/CSASI/0015/2017, awarded to MH], NMRC Centre Grant [CGAug16M012, awarded to EYT]. MyBrCa is funded by research grants from the Malaysian Ministry of Higher Education (UM.C/HIR/MOHE/06), the Wellcome Trust [grant no: v203477/Z/16/Z], and Cancer Research Malaysia.

\section{Availability of data and materials}

Data from each study were previously described (SGBCC [8], MyBrCa [9], and KOHBRA [10]). The genetic and clinical data used in this study were obtained via a data request (concept \#680) to the Breast Cancer Association Consortium (BCAC). All data requests can be directed to the BCAC data access committee (http://bcac.ccge.medschl.cam.ac.uk/ bcacdata/).

\section{Declarations}

Ethics approval and consent to participate

All studies were performed in accordance with the Declaration of Helsinki, and all participants provided written informed consent. SGBCC was approved by the National Healthcare Group Domain Specific Review Board (reference number: 2017/00797) and the Sing Health Centralised Institutional Review Board (reference number: 2016/3010). MyBrCa was approved by the Independent Ethics Committee, Ramsay Sime Darby Health Care (reference number: 201109.4 and 201208.1), and the Medical Ethics Committee, University Malaya Medical Centre (reference number: 842.9). KOHBRA has been reviewed and approved by the Institutional Review Board (reference number: B-0707-047-005) of each participating center.

\section{Consent for publication}

Not applicable.

\section{Competing interests}

The authors declare that they have no competing interests.

\section{Author details}

${ }^{1}$ Genome Institute of Singapore, Human Genetics, Singapore, Singapore. ${ }^{2}$ Saw Swee Hock School of Public Health, National University of Singapore and National University Health System, Singapore, Singapore. ${ }^{3}$ School of Mathematical Sciences, Faculty of Science and Engineering, University of Nottingham Malaysia, Jalan Broga, 43500 Semenyih, Selangor, Malaysia. ${ }^{4}$ Cancer Research Malaysia, 1 Jalan SS12/1A, 47500 Subang Jaya, Selangor, Malaysia. ${ }^{5}$ Subang Jaya Medical Centre, Jalan SS 12/1A, 47500 Subang Jaya, Selangor, Malaysia. ${ }^{6}$ Department of Surgery, Faculty of Medicine, University of Malaya, Kuala Lumpur, Malaysia. ${ }^{7}$ UM Cancer Research Institute, Kuala Lumpur, Malaysia. ${ }^{8}$ Department of Breast Surgery, Singapore General Hospital, Singapore, Singapore. ${ }^{9}$ Division of Surgical Oncology, National Cancer Centre Singapore, Singapore, Singapore. ${ }^{10}$ Department of General Surgery, Sengkang General Hospital, Singapore, Singapore. " Division of Breast Surgery, Changi General Hospital, Singapore, Singapore. ${ }^{12}$ Department of General Surgery, Tan Tock Seng Hospital, Singapore 308433, Singapore. ${ }^{13}$ Lee Kong Chian School of Medicine, Singapore, Singapore. ${ }^{14}$ Institute of Molecular and Cell Biology, Singapore, Singapore. ${ }^{15} \mathrm{KK}$ Breast Department, KK Women's and Children's Hospital, Singapore 229899, Singapore. ${ }^{16}$ Division of Radiation Oncology, National Cancer Centre Singapore, Singapore, Singapore. ${ }^{17}$ Lee Kong Chian School of Medicine, Nanyang Technology University, Singapore, Singapore. ${ }^{18} \mathrm{Cancer}$ Genetics Service, National Cancer Centre Singapore, Singapore, Singapore. ${ }^{19}$ Oncology Academic Clinical Program, Duke NUS, Singapore, Singapore. ${ }^{20}$ Division of Medical Oncology, National Cancer Centre Singapore, Singapore, Singapore. ${ }^{21}$ Department of Hematology-oncology, National University Cancer Institute, National University Health System, Singapore 119074, Singapore. ${ }^{22}$ Department of Surgery, University Surgical Cluster, National University Hospital, Singapore, Singapore. ${ }^{23}$ Department of Surgery, Breast Care Center, Daerim St. Mary's Hospital, Seoul, Korea. ${ }^{24}$ Department of Surgery, University of Ulsan College of Medicine and Asan Medical Center, Seoul, Republic of Korea.

${ }^{25}$ Department of Surgery, Soonchunhyang University and Hospital, Seoul, Republic of Korea. ${ }^{26}$ Department of Preventive Medicine, Seoul National University College of Medicine, Seoul, Republic of Korea. ${ }^{27}$ Department of Biomedical Sciences, Seoul National University College of Medicine, Seoul, Republic of Korea. ${ }^{28} \mathrm{Cancer}$ Research Institute, Seoul National University, Seoul, Republic of Korea. ${ }^{29} \mathrm{Centre}$ for Cancer Genetic Epidemiology, Department of Oncology, University of Cambridge, Cambridge, UK. ${ }^{30}$ Centre for Cancer Genetic Epidemiology, Department of Public Health and Primary Care, University of Cambridge, Cambridge, UK. ${ }^{31}$ Division of Molecular Pathology, Netherlands Cancer Institute, Antoni van Leeuwenhoek Hospital, Amsterdam, the Netherlands. ${ }^{32}$ Department of Surgery, Faculty of Medicine, University of Malaya, Jalan Universiti, 50630 Kuala Lumpur, Malaysia. 
${ }^{33}$ Department of Surgery, Yong Loo Lin School of Medicine, National University of Singapore and National University Health System, Singapore, Singapore.

Received: 25 March 2021 Accepted: 24 September 2021

Published online: 02 December 2021

\section{References}

1. Feng Y, Spezia M, Huang S, Yuan C, Zeng Z, Zhang L, et al. Breast cancer development and progression: risk factors, cancer stem cells, signaling pathways, genomics, and molecular pathogenesis. Genes Dis. 2018;5(2):77106. https://doi.org/10.1016/j.gendis.2018.05.001

2. Van 't Veer $L$, Dai H, Van de Vijver MJ, He YD, Hart AA, Mao M, et al. Gene expression profiling predicts clinical outcome of breast cancer. Nature. 2002; 415(6871):530-536, DOI: https://doi.org/10.1038/415530a.

3. Michailidou K, Lindstrom S, Dennis J, Beesley J, Hui S, Kar S, et al. Association analysis identifies 65 new breast cancer risk loci. Nature. 2017; 551(7678):92-4. https://doi.org/10.1038/nature24284.

4. Boyle EA, Li YI, Pritchard JK. An expanded view of complex traits: from polygenic to omnigenic. Cell. 2017;169(7):1177-86. https://doi.org/10.1016/j. cell.2017.05.038

5. Gibson G. Rare and common variants: twenty arguments. Nat Rev Genet 2012;13(2):135-45. https://doi.org/10.1038/nrg3118.

6. Li J, Ugalde-Morales E, Wen WX, Decker B, Eriksson M, Torstensson A, et al. Differential burden of rare and common variants on tumor characteristics, survival, and mode of detection in breast cancer. Cancer Res. 2018;78(21): 6329-38. https://doi.org/10.1158/0008-5472.CAN-18-1018.

7. Martin AR, Kanai M, Kamatani Y, Okada Y, Neale BM, Daly MJ. Clinical use of current polygenic risk scores may exacerbate health disparities. Nat Genet. 2019:51(4):584-91. https://doi.org/10.1038/s41588-019-0379-x.

8. Ho PJ, Yeoh YS, Miao H, Lim SH, Tan EY, Tan BKT, et al. Cohort profile: the Singapore Breast Cancer Cohort (SGBCC), a multi-center breast cancer cohort for evaluation of phenotypic risk factors and genetic markers. PLoS One. 2021;16(4):e0250102. https://doi.org/10.1371/journal.pone.0250102.

9. Tan MM, Ho WK, Yoon SY, Mariapun S, Hasan SN, Lee DS, et al. A case control study of breast cancer risk factors in 7,663 women in Malaysia. PLoS One. 2018;13(9):e0203469. https://doi.org/10.1371/journal.pone.0203469.

10. Han SA, Park SK, Ahn SH, Lee MH, Noh DY, Kim LS, et al. The Korean Hereditary Breast Cancer (KOHBRA) study: protocols and interim report. Clin Oncol (R Coll Radiol). 2011;23(7):434-41. https://doi.org/10.1016/j.clon.201 0.11 .007 .

11. Son BH, Ahn SH, Kim SW, Kang E, Park SK, Lee MH, et al. Prevalence of BRCA1 and BRCA2 mutations in non-familial breast cancer patients with high risks in Korea: the Korean Hereditary Breast Cancer (KOHBRA) Study. Breast Cancer Res Treat. 2012;133(3):1143-52. https://doi.org/10.1007/s1054 9-012-2001-0.

12. Goldhirsch A, Wood WC, Coates AS, Gelber RD, Thurlimann B, Senn HJ, et al. Strategies for subtypes--dealing with the diversity of breast cancer: highlights of the St. Gallen International Expert Consensus on the Primary Therapy of Early Breast Cancer 2011. Ann Oncol. 2011;22(8):1736-47. https:// doi.org/10.1093/annonc/mdr304.

13. Breast Cancer Association C, Dorling L, Carvalho S, Allen J, Gonzalez-Neira A Luccarini $C$, et al. Breast cancer risk genes - association analysis in more than 113,000 women. N Engl J Med. 2021;384(5):428-39. https://doi.org/10.1 056/NEJMoa1913948.

14. Rivas MA, Pirinen M, Neville MJ, Gaulton KJ, Moutsianas L, Go TDC, et al. Assessing association between protein truncating variants and quantitative traits. Bioinformatics. 2013;29(19):2419-26. https://doi.org/10.1093/ bioinformatics/btt409.

15. Li J, Wen WX, Eklund M, Kvist A, Eriksson M, Christensen HN, et al. Prevalence of BRCA1 and BRCA2 pathogenic variants in a large, unselected breast cancer cohort. Int J Cancer. 2019;144(5):1195-204. https://doi.org/10.1 002/ijc.31841.

16. O'Brien KM, Cole SR, Tse CK, Perou CM, Carey LA, Foulkes WD, et al. Intrinsic breast tumor subtypes, race, and long-term survival in the Carolina Breast Cancer Study. Clin Cancer Res. 2010;16(24):6100-10. https://doi.org/10.11 58/1078-0432.CCR-10-1533

17. Hu C, Polley EC, Yadav S, Lilyquist J, Shimelis $\mathrm{H}, \mathrm{Na}$ J, et al. The contribution of germline predisposition gene mutations to clinical subtypes of invasive breast cancer from a clinical genetic testing cohort. J Natl Cancer Inst. 2020; 112(12):1231-41. https://doi.org/10.1093/jnci/djaa023.
18. Dorling L, Carvalho S, Allen J, González-Neira A, Luccarini C, Wahlström C, et al. Breast cancer risk genes - association analysis in more than 113,000 women. N Engl J Med. 2021.

19. Lee $\mathrm{S}$, Abecasis GR, Boehnke M, Lin X. Rare-variant association analysis: study designs and statistical tests. Am J Hum Genet. 2014;95(1):5-23. https://doi.org/10.1016/j.ajhg.2014.06.009.

20. Mavaddat N, Michailidou K, Dennis J, Lush M, Fachal L, Lee A, et al. Polygenic risk scores for prediction of breast cancer and breast cancer subtypes. Am J Hum Genet. 2019;104(1):21-34. https://doi.org/10.1016/j.a jhg.2018.11.002

21. Guo MH, Plummer L, Chan YM, Hirschhorn JN, Lippincott MF. Burden testing of rare variants identified through exome sequencing via publicly available control data. Am J Hum Genet. 2018;103(4):522-34. https://doi. org/10.1016/j.ajhg.2018.08.016.

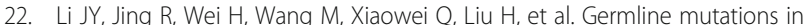
40 cancer susceptibility genes among Chinese patients with high hereditary risk breast cancer. Int J Cancer. 2019;144(2):281-9. https://doi.org/10.1002/ ijc.31601.

23. Wang YA, Jian JW, Hung CF, Peng HP, Yang CF, Cheng HS, et al. Germline breast cancer susceptibility gene mutations and breast cancer outcomes. BMC Cancer. 2018;18(1):315. https://doi.org/10.1186/s12885-018-4229-5.

24. Baretta Z, Mocellin S, Goldin E, Olopade Ol, Huo D. Effect of BRCA germline mutations on breast cancer prognosis: a systematic review and metaanalysis. Medicine (Baltimore). 2016;95(40):e4975. https://doi.org/10.1097/ MD.0000000000004975.

25. Zhu Y, Wu J, Zhang C, Sun S, Zhang J, Liu W, et al. BRCA mutations and survival in breast cancer: an updated systematic review and meta-analysis. Oncotarget. 2016;7(43):70113-27. https://doi.org/10.18632/oncotarget.12158.

26. Fasching PA. Breast cancer in young women: do $<$ em $>B R C A 1$ or $B R C A 2</$ em> mutations matter? Lancet Oncol. 2018;19(2):150-1. https://doi.org/10.1 016/S1470-2045(18)30008-1.

27. Bhoo-Pathy N, Hartman M, Yip CH, Saxena N, Taib NA, Lim SE, et al. Ethnic differences in survival after breast cancer in South East Asia. PLoS One. 2012;7(2):e30995. https://doi.org/10.1371/journal.pone.0030995.

28. Thirthagiri E, Lee SY, Kang P, Lee DS, Toh GT, Selamat $S$, et al. Evaluation of BRCA1 and BRCA2 mutations and risk-prediction models in a typical Asian country (Malaysia) with a relatively low incidence of breast cancer. Breast Cancer Res. 2008;10(4):R59. https://doi.org/10.1186/bcr2118.

29. van den Akker J, Hon L, Ondov A, Mahkovec Z, O'Connor R, Chan RC, et al. Intronic breakpoint signatures enhance detection and characterization of clinically relevant germline structural variants. J Mol Diagn. 2021;23(5):61229. https://doi.org/10.1016/j.jmoldx.2021.01.015.

30. Kwong A, Ng EK, Law FB, Wong HN, Wa A, Wong CL, et al. Novel BRCA1 and BRCA2 genomic rearrangements in Southern Chinese breast/ovarian cancer patients. Breast Cancer Res Treat. 2012;136(3):931-3. https://doi.org/1 0.1007/s10549-012-2292-1

31. Seong MW, Cho SI, Noh DY, Han W, Kim SW, Park CM, et al. Low contribution of BRCA1/2 genomic rearrangement to high-risk breast cancer in the Korean population. Fam Cancer. 2009;8(4):505-8. https://doi.org/10.1 007/s10689-009-9279-z.

32. De La Vega FM, Bustamante CD. Polygenic risk scores: a biased prediction? Genome Med. 2018:10(1):100. https://doi.org/10.1186/s13073-018-0610-x.

33. Cadiz F, Kuerer HM, Puga J, Camacho J, Cunill E, Arun B. Establishing a program for individuals at high risk for breast cancer. J Cancer. 2013;4(5): 433-46. https://doi.org/10.7150/jca.6481.

34. Duffy SW, Tabar L, Olsen AH, Vitak B, Allgood PC, Chen TH, et al. Absolute numbers of lives saved and overdiagnosis in breast cancer screening, from a randomized trial and from the Breast Screening Programme in England. J Med Screen. 2010;17(1):25-30. https://doi.org/10.1258/jms.2009.009094.

\section{Publisher's Note}

Springer Nature remains neutral with regard to jurisdictional claims in published maps and institutional affiliations. 